Article

\title{
Thermal and Fire Characteristics of FRP Composites for Architectural Applications
}

\author{
Umberto Berardi ${ }^{1, *}$ and Nicholas Dembsey ${ }^{2}$ \\ Received: 5 September 2015 ; Accepted: 4 November 2015 ; Published: 11 November 2015 \\ Academic Editors: Alper Ilki and Masoud Motavalli \\ 1 Department of Architectural Science, Ryerson University, 350 Victoria Street, Toronto, \\ ON M5B 2K3, Canada \\ 2 Fire Protection Engineering Department, Worcester Polytechnic Institute, 100 Institute Road, Worcester, \\ MA 01609, USA; ndembsey@wpi.edu \\ * Correspondence: uberardi@ryerson.ca; Tel.: +1-416-979-5000 (ext. 3263); Fax: +1-416-979-5000
}

\begin{abstract}
This paper discusses the main challenges of using fiber reinforced polymers (FRPs) in architectural applications. Architects are showing increased interest in the use of FRPs in modern buildings thanks to FRPs' ability to allow cost effective realization of unique shapes and flexible aesthetics, while accommodating architectural designs and needs. The long-term durability, weathering resistance, and the exceptional mechanical properties have recently suggested the adoption of FRPs for building façade systems in an increasing number of buildings worldwide. However, some challenges for a wider adoption of FRPs in buildings are represented by the environmental and thermal aspects of their production, as well as their resistance to the expected "fire loads". This last aspect often raises many concerns, which often require expensive fire tests. In this paper, the results of cone calorimeter tests are compared with software simulations to evaluate the possibility of designing FRPs on the computer as opposed to current design practice that involves iterative use of fire testing. The comparison shows that pyrolysis simulations related to FRPs are still not an effective way to design fire safe FRPs for architectural applications.
\end{abstract}

Keywords: fiber reinforced polymer; polymers; modern architecture; buildings; high performance envelopes; building enclosure; fire safety; fire performance assessment

\section{Introduction}

Although the building industry is often considered a "low technology" sector, architects have always shown strong interest in new building materials. Among these fiber reinforced polymers (FRPs), also known as advanced polymer composites, have recently attracted a lot of interest due to their high strength to weight ratio, ease of producing unique shapes, flexible aesthetics, low thermal transmissibility and low carbon footprint in a life-cycle perspective [1,2]. FRPs are obtained from fibers, which impart strength and stiffness to the composite, and a thermosetting polymer matrix which binds the fibers together, transferring loads from fiber to fiber, while protecting these from the surrounding environment.

Although some doubts about the durability of FRPs are sometimes raised, these material have repeatedly proved exceptional durability and corrosion resistance compared to common building materials [3]. Properly fabricated FRPs do not rot like wood or rust like steel, have very good resistance to chemical corrosion, and their multi-decades of use in the boat industry shows that they are efficient in environments where other typical materials will be unsuitable.

Given these substantial characteristics, FRPs must still demonstrate sound performance related to elevated temperature, especially expected "fire loads" (design fires) to contribute to a building's 
passive protection to ensure life safety and property protection in case of fire [4]. Moreover, the increasing awareness towards building energy saving and more in general towards sustainability issues, suggests the use of FRPs in modern building construction.

The more appropriate and rigorous method of evaluating the environmental impact of a material is a Life Cycle Assessment (LCA). This is a complicated assessment which is valid only for a specific material system in a specific project [5]. In general, comparing the same weight of different materials, FRPs generally require more energy to produce than other substitutable products but since the weight of a product plays a significant role for the environmental impacts of transportation, installation, and back-up structure, a proper LCA is not easy. So while, intuition suggests that FRPs would not be a very "green" solution since it comes from petroleum, surprisingly, this assumption is often wrong because of the high strength to weight of the FRPs, so small quantity of FRPs that is normally used, plus the long-term durability of FRPs, when compared with more conventional materials, also play an important role. Recently, some comparisons between FRPs panels and equivalent reinforced concrete have shown that it is the resin used in the FRPs which contributes to most of the environmental impacts, and so new studies are trying to off-set also this aspect [1,6].

A wide variety of fibers and/or matrices can be used for FRPs. The three fibers which are often selected for FRPs are glass, aramid and carbon fibers. Similarly, the thermosetting matrices which are utilized for composite structural members in civil infrastructure are vinyl-esters, epoxies and polyesters. Cost limitations and durability issues for architectural applications makes glass fiber and polyester resin the most commonly used composition of fiber and matrix. However, some biodegradable composite resins and high-strength natural fibers have been developed recently too [7].

This paper focuses on two non-structural aspects of FRPs, mainly their thermal transmissibility and fire pyrolysis behavior. Although FRPs have good performance related to low thermal loads, their fire safe behavior needs to be demonstrated for the application of interest. In particular, this paper shows that computer pyrolysis simulations are not yet sufficiently accurate to allow practical design of fire safe FRPs. The object of this paper is limited to FRPs for architectural applications only, and does not consider typical cases of civil engineering where FRPs are used in combination with other engineering materials to improve the stiffness, strength and durability of an overall composite structural system.

\section{Brief Review of FRPs Use in Buildings}

Although FRPs seem to be an innovative family of materials with new applications developing on an ongoing basis, FRPs have been used for a long time in the construction industry.

In the 1970s, FRP composites started to be considered as a building material to design composite building structures. Larger fabricating firms, which already had experience of manufacturing FRPs for other industries, proposed semi-load bearing and infill panels for houses and larger constructions. The classroom structure at Fulwood in Lancashire, the Mondial House in London or the Amex House in Brighton are examples of these early applications. In particular, the Mondial House, a large modern building with a $46 \mathrm{~m}$ height, was built in London in 1974, almost entirely cladded with FRP panels (Figure 1). The cladding panels had a fluted surface and were $3 \mathrm{~m}$ high $\times 1.8 \mathrm{~m}$ wide, except for the panels on the eighth floor, which were $6.7 \mathrm{~m}$ high [2]. The panels were reinforced with foam cores and top hat stiffeners. They were molded using fire retardant polyester laminating resin and isophthalic polyester gel-coat for good weathering resistance and durability, and in fact they sowed minimal aging after over 30 years from their installation [2]. A core material of rigid polyurethane foam bonded to the outer skin and covered on the back with a further glass reinforced laminate guaranteed some degree of rigidity, as well as low thermal conductivity.

Although FRPs have good building science properties, the architectural embellishment motivated the early applications of FRP composite materials in first modern buildings. By the mid-1980s there was a desire to use FRPs as a structural material in order to replace the more 
conventional civil engineering materials in aggressive and hostile environments with a durable, high-strength and high stiffness material.

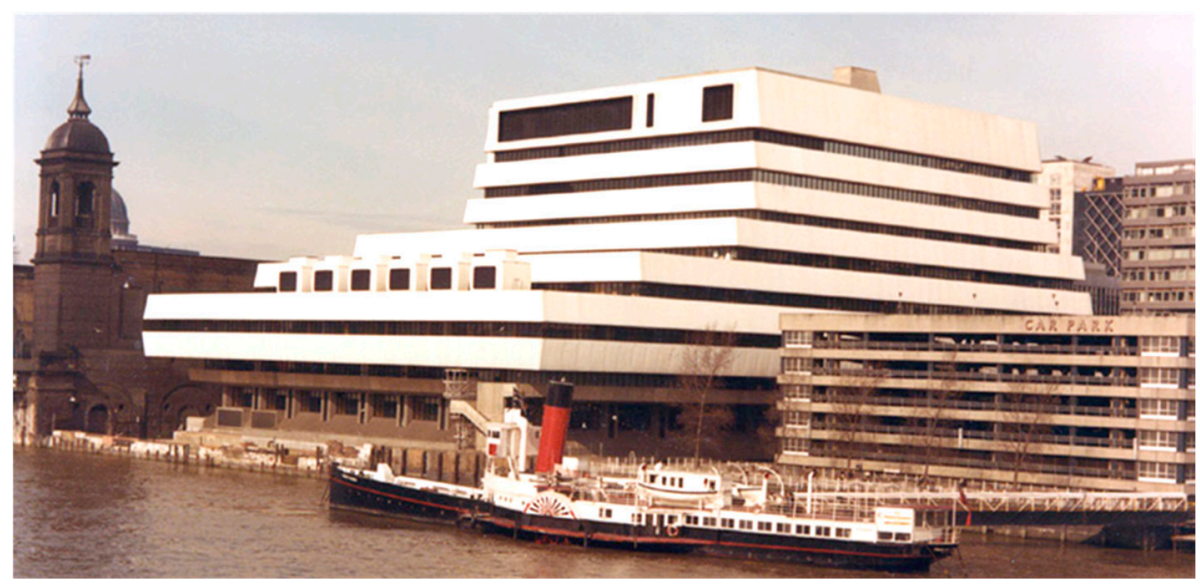

Figure 1. Mondial House, in London, built in 1974 and demolished in 2006.

Until the 1990s, FRP applications were often interested to small building components, such as dormer windows, canopies, and cladding, where FRPs acted as a secondary structure supported by conventional construction materials. In rare cases, FRPs were used to produce self-supporting large structures such as curved elements, which would have been difficult and expensive to build with conventional materials. The GFRP Eyecatcher building built in Switzerland in 1998, was among the first to show the great potential of FRPs as a primary structure. This 15 meter tall building with five floors showed the advantages of load bearing structure made exclusively of GRP systems such as avoiding thermal bridges. The building was first used at a building fair (Swissbau99), subsequently disassembled and re-assembled.

Many examples of FRPs use have followed. In particular, pultruded structural shapes for civil engineering (including wind tower elements), bridge decks, FRP enhanced pre-stressed concrete or externally bounded reinforcements using FRPs (as strips or sheets) are among the most common applications nowadays, although they are beyond the interest of this paper, which is limited to building applications where FRP applications satisfy the desire for more dramatic features in high performance building enclosures.

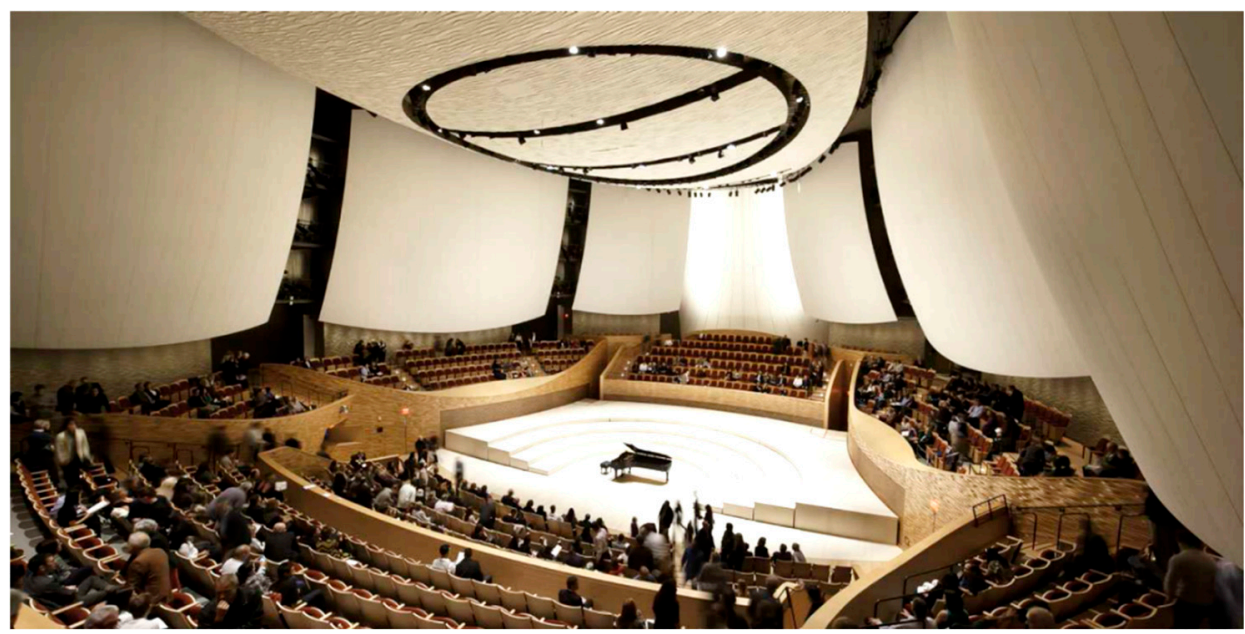

Figure 2. Interior of the Bing Concert Hall in Stanford, CA, USA, completed in 2011. 
The recently completed Bing Concert Hall in Stanford is one of the largest applications of FRPs for interior finishing and has demonstrated that FRPs could be produced and sustained in large dimensions (Figure 2). So as shapes start to become a part of the architectural design, the potential for using the shape structurally begins to occur more clearly. While FRPs are still often used for interior applications, recent examples of use of FRPs use in large facades are also increasing. For example, the One Ocean Thematic pavilion for the 2012 Yeosu Expo in South Korea designed by SOMA has largest FRP beams which were used as fascinating architectural textures (Figure 3).

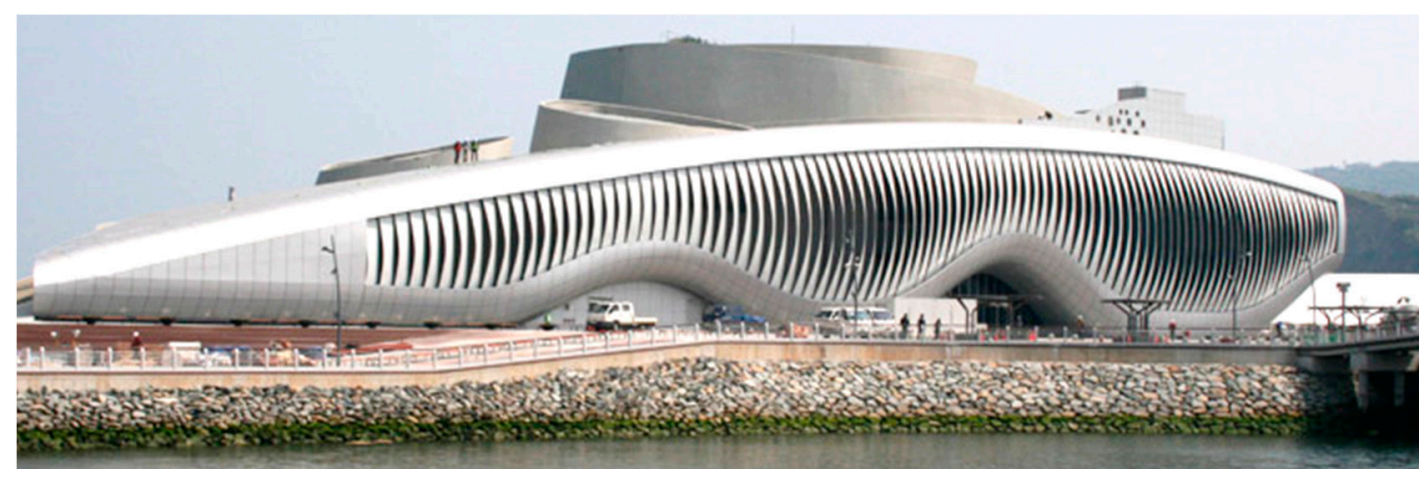

Figure 3. One Ocean Thematic Pavilion for Yeosu Expo 2012 South Korea designed by SOMA.

Kreysler and Associates have recently developed a new ultra-lightweight FRP cladding panel system, which is believed to be the first fire-resistant FRP cladding panel to pass the NFPA 285 test [8]. This test involves construction of a full-scale mockup of a multistory façade system, which is then burned for fire propagation characteristics. Large cladding systems such as this allow designers to utilize fully the potential of customized and digitally-fabricated composite cladding, and to create large and high-rise facades of almost any shape, contour and texture. Thanks to FRPs, designers can give their buildings shapes that would be too expensive and too heavy to execute with conventional construction materials, while meeting also the code fire safety requirements.

An example of the capabilities of this new system is displayed in the new San Francisco Museum of Modern Art expansion, designed by Norway-based practice Snøhetta (Figure 4). The 10-story façade has a horizontal texture recalling the waters of San Francisco Bay, and was obtained using 710 FRP panels, with a skin thickness smaller than $5 \mathrm{~mm}$, which were mechanically fastened and bonded to the unitized wall using a custom aluminum extrusion. These FRP panels were created from CNC-milled recyclable EPS foam molds [3]. The low weight of only $0.2 \mathrm{~kg} / \mathrm{m}^{2}$ allowed to install panels as large as $1.7 \mathrm{~m} \times 9.1 \mathrm{~m}$.

\section{Low Thermal Conductivity}

So far the main reasons for using FRPs in architectural applications has been related to their high mechanical properties as well as for their lightweight and customized shape. However, the low thermal transmissibility make FRP panels good candidates for façade applications too $[9,10]$.

The thermal conductivity of all polymers is low, which means that FRPs are good heat insulators. These favorable properties of FRP composites are based on the low density of the matrix resins used, and the high strength of the embedded fibers. Thermal conductivity of the GFRP composite laminates is dependent on such factors as epoxy-filler interaction and filler characteristics, namely type and shape of filler. To reduce the thermal conductivity of a polymer further the material can be used in the form of a foam. Devendra and Rangaswamy compared the thermal conductivity and thermal expansion coefficients of glass fiber reinforced epoxy composites fabricated by filling with varying concentrations of fly ash, stone powder, aluminum oxide, magnesium hydroxide, silicon carbide particles and hematite powder [9]. The test results show that fly ash filled glass FRPs (GFRPs) 
exhibited the lowest thermal conductivity $\left(1.23 \mathrm{~W} / \mathrm{m} \cdot{ }^{\circ} \mathrm{C}\right)$, while GFRP laminates filled with silicon carbide particles exhibited the maximum thermal conductivity $\left(3.51 \mathrm{~W} / \mathrm{m} \cdot{ }^{\circ} \mathrm{C}\right)$.

Table 1 reports a comparison for typical building material properties between FRPs and other building materials. This comparison shows that being much lighter than other typical materials used for structural elements in buildings, FRPs have a thermal conductivity which is almost as low as that of wood, without being affected by the moisture content, as it is for the wood.

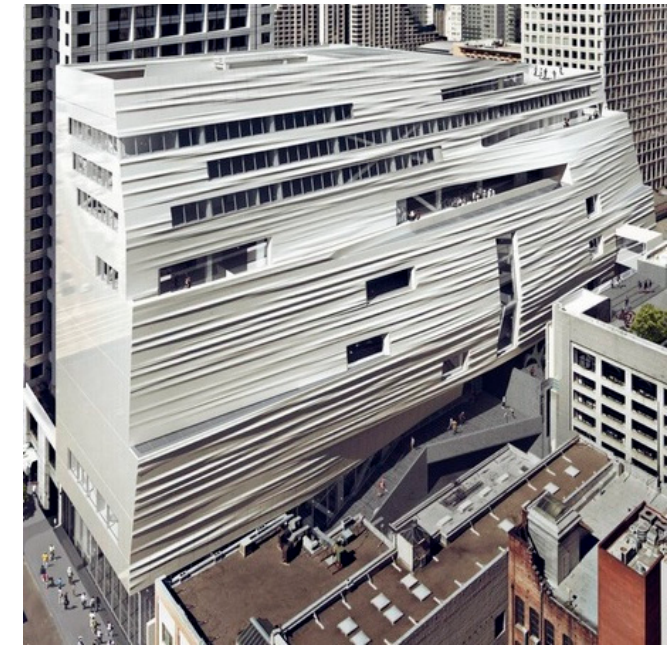

(a)

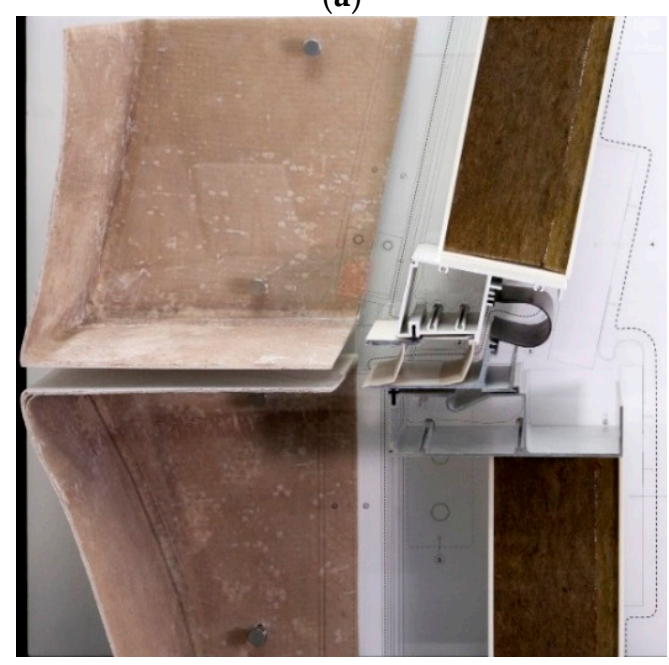

(c)

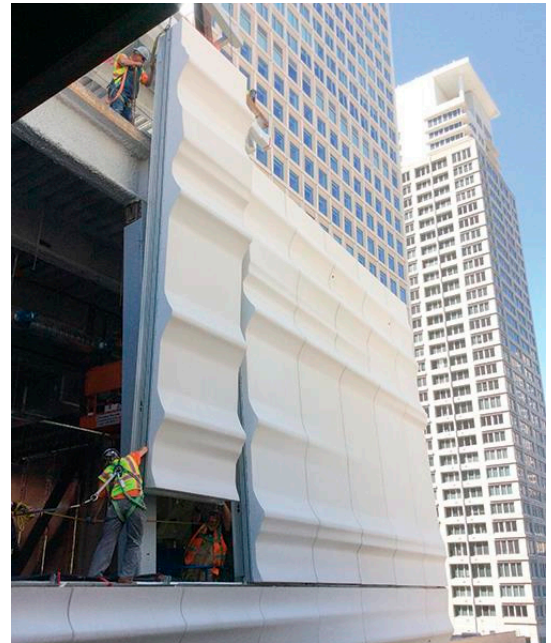

(b)

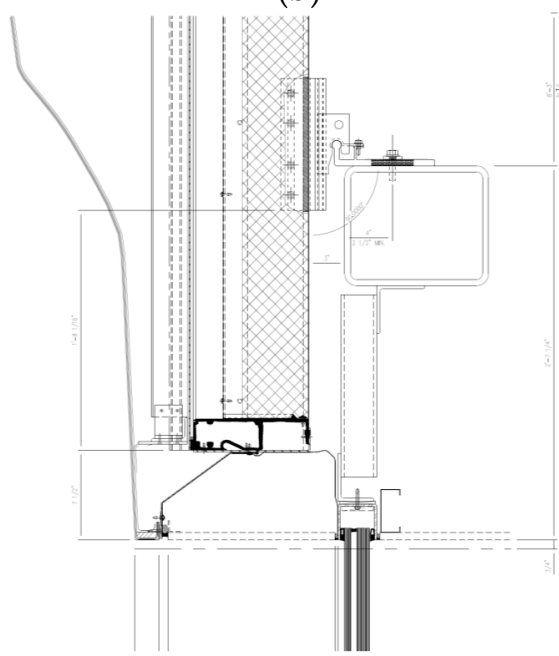

(d)

Figure 4. East facade (a), photo of the mounting phase (b), and detail (c and $\mathbf{d}$ ) of the fiber reinforced polymer (FRP) panels of the expansion to the San Francisco Museum of Modern Art, opening in 2016.

Table 1. Main characteristic values for FRPs and other traditional building materials. FRPs data have been elaborated from $[1,6,7]$.

\begin{tabular}{ccccc}
\hline Characteristics & FRPs & Steel & Wood & Concrete \\
\hline Tensile strength $(\mathrm{MPa})$ & 170 to 270 & 450 & low & 2 to 5 \\
Flexural strength $(\mathrm{MPa})$ & 205 to 240 & 450 & 80 & 3 to 5 \\
Density $\left(\mathrm{kg} / \mathrm{m}^{3}\right)$ & 1,550 & 7,500 & 200 to 1,400 & 2,200 \\
Thermal conductivity $\left(\mathrm{W} / \mathrm{m} \cdot{ }^{\circ} \mathrm{C}\right)$ & 0.57 & 46.55 & 0.15 to 0.04 & 0.8 \\
Thermal expansion $\left(10^{-6} \mathrm{~m} / \mathrm{m} \cdot{ }^{\circ} \mathrm{C}\right)$ & 20 & 12 & 3 & 14.5 \\
\hline
\end{tabular}


Moreover, the high durability of the FRPs guarantees that these have a much more stable behavior in terms of thermal conductivity and do not suffer aging and weathering.

Polymer permeability to moisture diffusion is generally under evaluated. However, moisture diffusion may also affect the chemical and thermo-physical characteristics of polymers. In particular, the absorption of the moisture may cause mechanisms such as plasticization, saponification or hydrolysis in the structure of the polymer [1]. Within FRP composites, the polymer matrix offers the fiber some protection from moisture attack, although, it is relatively less efficient at normal fiber volume fractions of $60 \%$. Methods to decrease the permeability of FRP composites are either the application of a coating (gel-coat) to the outer surface of FRP structures or the inclusion of coupling agents applied directly onto the fiber at the time of manufacture.

Bai et al., performed fire endurance experiments on cellular GFRP slabs, DuraSpan 766 slab system from Martin Marietta Composites, and found a thermal conductivity of $0.35 \mathrm{~W} / \mathrm{m} \cdot \mathrm{K}$, while the thermal conductivity of fiber and of the resin were $1.1 \mathrm{~W} / \mathrm{m} \cdot{ }^{\circ} \mathrm{C}$ and $0.2 \mathrm{~W} / \mathrm{m} \cdot{ }^{\circ} \mathrm{C}$ respectively [11].

Studies on natural fibers for advanced composites have shown that natural fibers have a hollow portion resulting in better thermal insulation property. In particular, the thermal conductivity of natural fiber-reinforced composites decreases with increasing fiber content. The thermal conductivity of $0.3 \mathrm{~W} / \mathrm{m} \cdot{ }^{\circ} \mathrm{C}$ for a $40 \%$ of fiber reduced to less than $0.2 \mathrm{~W} / \mathrm{m} \cdot{ }^{\circ} \mathrm{C}$ for a $70 \%$ content of fiber [7].

A successful method to decrease heat diffusion for civil engineering polymers is to apply an additive to the matrix polymer at the time of manufacture. However, the utilization of nano-composites is expensive for architectural applications and it is generally avoided.

One of the importance aspects related to heat and FRPs is the thermal expansion, the change in length per unit rise in temperature. The importance of this property is given by the fact that FRPs have a thermal expansion that can be up to an order higher than those of the conventional civil material [12].

An interesting example of using FRPs as the only material for a high performing house was demonstrated in Solatrium, a Solar Decathlon project [13]. The sandwich FRP panels used in this house Transonite ${ }^{\circledR}$ consisted of two GFRP face sheets and a foam core. In these panels, the two face sheets are bonded together with through-thickness fiber insertions (Figure 5). The glass fibers in the skins consist of four plies of $0.848 \mathrm{~kg} / \mathrm{m}^{2}$ woven roving oriented in two different directions. The total thickness of the panel was $89 \mathrm{~mm}$, while the core poly-isocyanurate (PIR) foam was $80 \mathrm{~mm}$ thick. This core resulted in an overall thermal conductivity of only $0.48 \mathrm{~W} / \mathrm{m}^{2} \cdot \mathrm{K}$.
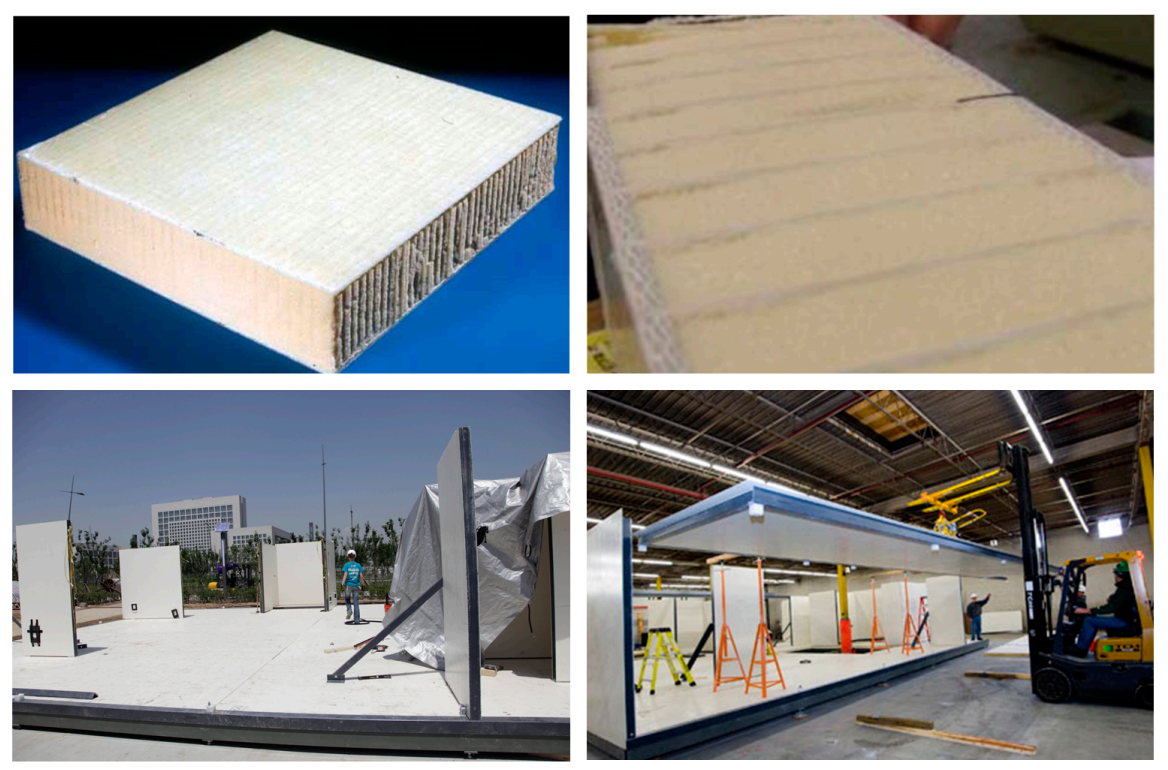

Figure 5. Photos of the FRP Transonite ${ }^{\circledR}$ panel and their use in the Solar Decathlon project Solatrium. 
The selection of FRP panels in this high performance house was motivated mainly with their lightness. However, also in such a single storey house, some issues related to the fire safe performance of the panels had to be addressed. The smoke production from the panels under fire conditions was unacceptable, so that an intumescent coating was used as passive fire protection system to treat the surface of the FRP composites [4].

\section{Fire Performance Behavior}

Previous sections have shown many advantages of FRPs in architectural applications. However, given the commonly perceived limits of FRPs under fire attacks, it is often important for the architect, engineer and fabricator to be able to demonstrate that a given FRP material system and/or assembly is fire safe. The current practice involving simple correlations will be discussed followed by current work evaluating comprehensive pyrolysis models for simulation of FRP fire behavior.

\subsection{Current Practice}

When FRP is used as a material system or part of an assembly in the built environment it must meet local building code requirements to demonstrate that it is fire safe. One example of these requirements is the International Building Code (IBC) that is used as amended locally in the USA [14]. For interior finish applications the IBC requires that material systems such as FRPs demonstrate certain flame spread and smoke characteristics as measured in the intermediate scale test ASTM E84 (Tunnel Test) [15], for exterior use applications the IBC requires that assemblies built from material systems such as FRPs demonstrate certain flame spread characteristics as measured in the full scale test NFPA 285 (Multi-story Building Test) [8].

Neither one of these tests is particularly useful for material systems and/or assembly design due to the size and cost of specimens required to run each test. Ideally, computer simulation could be used to design material systems and/or assemblies that are fire safe. Given the state of the art in fire growth modeling, computer simulation of fire tests such as ASTM E84 and NFPA 285 is not yet practical for architects, engineers and fabricators on a day to day basis in order to design FRPs on the computer.

Fortunately, bench scale fire tests of material systems and simple correlations can be used in a screening process to predict standard fire test performance. For example, a bench scale test of interest is the ASTM E1354 [16]. This test method allows for a wide range of FRP component characteristics to be evaluated in a cost effective manner. In this test various indirect measurements are taken which provide characteristics of the heterogeneous (macro) system that can be correlated with intermediate and full scale test performance. A screening process for ASTM E84 [17] and a screening process for NFPA 285 [18] have been developed recently.

Similarly, Nguyen et al., have recently showed an intermediate scale experiment with single burning item (SBI) for testing the fire resistance of FRP composite building facade. This modeling involves both simulation of gas phase flames and fire spread processes as well as pyrolysis of condensed phase fuel [19].

The advantage of screening processes is that the heterogeneous (macro) characteristics of various FRP systems can be rapidly evaluated and the optimal candidate systems for intermediate and full scale testing can be readily identified. The disadvantage of these screening processes is that more fundamental pyrolysis behavior is not measured, and so an advanced development of fire growth modeling is not possible. This paper will hence focus only on the condensed phase fuel in terms of pyrolysis modeling.

\subsection{Comprehensive Pyrolysis Models}

The state of the art fire growth modeling research is based on CFD gas phase fire model [20] and comprehensive condensed phase pyrolysis models [21,22]. These pyrolysis models are formulated to simulate fundamental material systems' behavior. In part this is accomplished by simulating 
the behavior of systems' component species. For FRPs these species are: resin, additives and glass fiber, and any intermediate and residue species resulting from thermal decomposition. Each species requires a set of thermal and decomposition parameters.

Recent work on estimation of material system pyrolysis parameters discusses the challenges faced in measuring and/or optimizing these [23,24]. To keep parameter sets from becoming impractically large, simplified decomposition reactions are important [25]. To develop the most robust parameters (effective properties) it is important to properly identify FRP component species [26]. Pyrolysis parameters that have been estimated for a common FRP material system are modified acrylic resin, alumina trihydrate $(\mathrm{ATH})$ and glass fiber $[23,26]$.

\section{Evaluation of Comprehensive Pyrolysis Models}

Given the ability to estimate pyrolysis parameters for a given FRP system, it is of interest to evaluate ability of comprehensive models to simulate behavior of a whole class of FRP systems. If a comprehensive model can successfully simulate the behavior of a class of FRP systems then the model has the potential to be used as a design tool.

To better understand how component species in FRP material systems affect pyrolysis simulation, a common class of systems was considered. This class of unsaturated polyester resin (Hetron $^{\mathrm{TM}} 650$ T20 manufactured by Ashland Performance Materials) and ATH additive mixed in various ratios, and glass fiber. Both the resin and ATH undergo thermal decomposition, while the glass can be considered as inert when exposed to high temperatures. Given this decomposition behavior, it makes sense to simplify the evaluation by considering only the resin and ATH initially. If the comprehensive model is successful then adding the glass fiber to the evaluation will be the next logical step.

Previous works by Kim [23,26] with a similar FRP system with modified acrylic resin, ATH and glass fiber, defined the following species: resin, resin residue, ATH, ATH residue and glass fiber. It is important to understand that Kim's work was based on one ratio of resin and ATH mixture. Analysis of TGA [27] and DSC [28] data on this one mixture of resin and ATH showed that decomposition of the resin and ATH can both be reasonably modeled as single step reactions. Based on these species and the optimized kinetic models for the two reactions, pyrolysis parameters were estimated for all the species. Previous work by Dembsey et al. [29] measured the kinetic parameters for cured pure Hetron resin and pure ATH powder but did not measure thermal parameters. Given the similarity between the FRP system considered by Kim and by Dembsey et al., resin and ATH parameters from both efforts will be used.

\subsection{Resin and ATH Specimens}

To evaluate the decomposition of Hetron resin and ATH mixtures, 1D slabs were produced that had the following mass ratios of resin to ATH additive: 100:0 (pure resin), 100:33, 100:66, 100:100 and 100:130. Further details on the slabs are shown in Table 2.

\subsection{Cone Calorimeter}

To determine the pyrolysis behavior of the 1D slabs the bench scale apparatus the Cone Calorimeter was used [16]. Typically the Cone exposes $100 \mathrm{~mm}$ by $100 \mathrm{~mm}$ samples to a nominally uniform incident heat flux (IHF). In this work due to the limited number of samples the choice was made to cut samples to $50 \mathrm{~mm}$ by $50 \mathrm{~mm}$ so that a sufficient number of samples could be tested for repeatability. The behavior of the smaller samples was confirmed to be consistent with that of the larger samples. The direct measurements taken by the Cone apparatus allow various heat release rate, mass loss rate and smoke parameters to be indirectly measured during a specimen burn. An IHF of $50 \mathrm{~kW} / \mathrm{m}^{2}$ was used for all samples. Sample sides and bottom were wrapped in aluminum foil. The wrapped samples were mounted on an insulation substrate. Additionally, 30 gauge Type $\mathrm{K}$ thermocouples (TCs) were attached to the exposed and unexposed face of the samples. The exposed 
face TC was mechanically pressed against the sample surface. The unexposed face TC was glued to the sample surface using a small amount of high temperature cement.

Table 2. Hetron and ATH 1D slabs.

\begin{tabular}{ccccc}
\hline $\begin{array}{c}\text { Sample } \\
\text { Number }\end{array}$ & $\begin{array}{c}\text { Composition } \\
\text { (Hetron:ATH) }\end{array}$ & Weight $(\mathbf{g})$ & $\begin{array}{c}\text { Thickness } \\
(\mathbf{m m})\end{array}$ & $\begin{array}{c}\text { Dimensions } \\
(\mathbf{m m} \times \mathbf{m m})\end{array}$ \\
\hline 1 & & 29.39 & 7.20 & \\
2 & $100: 130$ & 32.38 & 7.55 & $50 \times 50$ \\
3 & & 27.33 & 7.10 & \\
4 & 30.85 & 7.50 & $50 \times 50$ \\
\hline 5 & & 24.94 & 6.40 & \\
6 & $100: 100$ & 27.24 & 6.90 & $50 \times 50$ \\
7 & & 26.60 & 6.80 & \\
8 & & 26.85 & 6.50 & \\
\hline 9 & & 17.27 & 4.70 & $50 \times 50$ \\
10 & $100: 66$ & 17.78 & 4.70 & \\
11 & & 21.30 & 5.20 & \\
12 & & 20.38 & 5.30 & \\
\hline 13 & & 15.39 & 4.50 & $50 \times 50$ \\
14 & $100: 33$ & 16.00 & 4.90 & \\
15 & & 17.03 & 4.90 & \\
16 & & 15.60 & 4.40 & \\
\hline 17 & & 11.14 & 3.60 & \\
18 & & 9.69 & 3.30 & \\
19 & & 11.60 & 3.95 & \\
20 & & 11.56 & 3.60 & \\
\hline
\end{tabular}

\subsection{Gpyro Modeling}

Gpyro is a generalized pyrolysis model that can be applied to a wide variety of condensed phase fuels. The model simultaneously calculates the condensed phase mass conservation, gas phase mass conservation, condensed phase species conservation, and condensed phase energy conservation equations. The resin and ATH mixtures are considered to be homogeneous. Gas phase decomposition products are assumed to be released instantaneously. Local thermal equilibrium is assumed between the condensed phase and the decomposition products. As the specimen decomposes its volume is assumed constant which means that the final residue forms a porous char.

\subsubsection{D Slab Model}

Consistent with the Cone sample mounting the exposed face of the sample was assumed to have a constant IHF boundary condition with radiative and convective cooling to the ambient surroundings. The heat flux from the burning sample after ignition was not included in the model. The back face of the sample was allowed to lose heat via a contact conductance. The model thickness was set to match the physical thickness of the samples (Table 2). Approximately 400 cells were used across the thickness.

The specimen is assumed to consist of four species: resin, resin residue, ATH, and ATH residue. Each species has its own thermal properties. The resin and ATH each undergo their own one-step decomposition reaction starting with the virgin material, and producing gas and residue as decomposition products. The decomposition is modeled as an nth order reaction, as reported in Equation (1). Each decomposition reaction is endothermic and its energetics is characterized by a heat of decomposition $(\Delta H)$.

$$
\frac{\mathrm{d}(1-\propto)(t)}{\mathrm{d} t}=\left[\operatorname{Aexp}\left(-\frac{E_{a}}{\mathrm{R} T(t)}\right)\right](1-\propto(t))^{n}
$$


where: $\alpha=1-\left(m / \mathrm{m}_{\mathrm{o}}\right), E_{\alpha}=$ activation energy $(\mathrm{kJ} / \mathrm{mol}), t=$ time $(\mathrm{min}), \mathrm{R}=$ ideal gas constant $(8.314 \mathrm{~J} / \mathrm{molK}), m=$ mass of sample $(\mathrm{kg}), T=$ temperature $(\mathrm{K}), \mathrm{m}_{\mathrm{o}}=$ initial mass of sample $(\mathrm{kg})$, $n=$ exponent, and $\mathrm{A}=$ pre-exponential constant $(1 / \mathrm{s})$.

\subsubsection{Input Parameters}

Other than the input parameters described above or noted, Gpyro default parameters were used. Tables 3 and 4 the input parameters for each species. These values were determined based on previous work $[23,26,29]$.

Table 3. Species thermal properties.

\begin{tabular}{|c|c|c|c|c|}
\hline Species & $\begin{array}{c}\text { Thermal conductivity } k \\
(\mathrm{~W} / \mathrm{m} \cdot \mathrm{K})\end{array}$ & $\begin{array}{c}\text { Density } \\
\rho\left(\mathrm{kg} / \mathrm{m}^{3}\right)\end{array}$ & $\begin{array}{l}\text { Specific heat } \\
c(\mathrm{~kJ} / \mathrm{kg} \cdot \mathrm{K})\end{array}$ & $\begin{array}{l}\text { Emissivity } \\
\varepsilon\end{array}$ \\
\hline Hetron & 0.23 & 1,200 & 1.40 & 0.84 \\
\hline Hetron Residue & 0.19 & 253 & 1.90 & 0.90 \\
\hline ATH & 1.22 & 2,300 & 1.20 & 0.81 \\
\hline ATH Residue & 0.24 & 1,558 & 1.20 & 0.89 \\
\hline
\end{tabular}

Table 4. Species decomposition properties.

\begin{tabular}{ccccc}
\hline Species & $\log _{\mathbf{1 0}} A\left(\mathbf{s}^{-1}\right)$ & $\boldsymbol{E}(\mathbf{k J} / \mathbf{m o l})$ & $\Delta \boldsymbol{H} \mathbf{( k J} / \mathbf{k g})$ & $n$ \\
\hline Hetron to Hetron & 13.7 & 195 & 172 & 1.125 \\
Residue & 11.4 & 140.1 & 1,000 & 1.24 \\
ATH to ATH Residue & 1.4 & \\
\hline
\end{tabular}

\subsection{Results}

Figure 6 shows samples of each resin and ATH mixture post-test. Samples 1 and 5 burned with similar characteristics and both showed surface charring and longer overall burn time. Samples 9 and 13 also showed charring characteristics and both had a thin top layer which rose off the bulk of the sample during burning and revealed a charred layer underneath. Sample 17 displayed intumescent-like characteristics. Physically, all of the sample ratios showed some minimal increase in thickness but may all be considered geometrically stable.

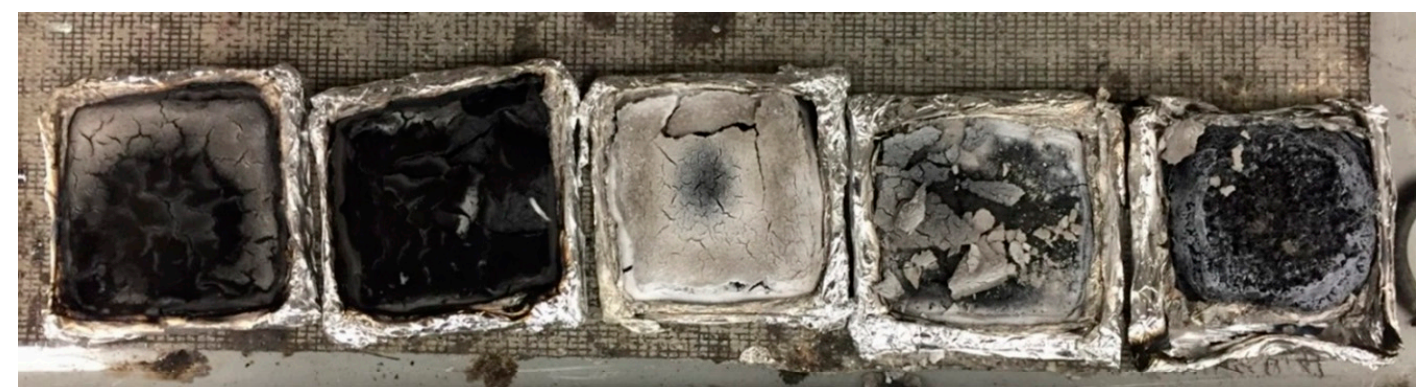

Figure 6. Photos of the different samples after the tests. From left to right: sample 1 (100:130), sample 5 (100:100), sample 9 (100:66), sample 13 (100:33), and sample 17 (100:0).

Figure 7 shows the mass loss rate per unit area (MLRPUA) and the exposed face and unexposed face temperatures for both the Cone experiments and the Gpyro simulations. The Cone results are average values of the tests. Both MLRPUA and temperature are plotted versus a normalized time variable Tau. Tau is time divided by sample thickness squared. It allows for samples of different thickness to be compared on the same heat diffusion basis. 
The Cone experiments show that as the mass fraction of ATH is increased the MLRPUA decreases and the burn duration decreases. When the mixture ratio of resin to ATH is in the range of 100:66 to 100:130, approximate limit to the MLRPUA at $10 \mathrm{~g} / \mathrm{m}^{2} \mathrm{~s}$ emerges. For the mixture ratios in the range 100:0 to 100:66, the peak of MLRPUA occurred toward the end of the experiment. This effect is due to the sample producing less of a blockage layer (ATH residue) and the undecomposed sample becoming "thermally thin".

The Gpyro simulations for MLRPUA show the same general ranking as that in the Cone based on mixture fraction of ATH. For the mixture 100:0, the simulated history has a good correspondence to the Cone measured history based on MLRPUA magnitudes and burn duration. For the mixtures 100:33 to 100:130 the simulated MLRPUA values are significantly larger than those measured in the cone, while the corresponding simulated burn durations are significantly shorter.

The inability of the Gpyro model to track the MLRPUA behavior for increasing levels of ATH is not surprising as mass transport through the porous residue layer is not modeled. Not modeling the porous residue was necessary due to a lack to relevant parameters.

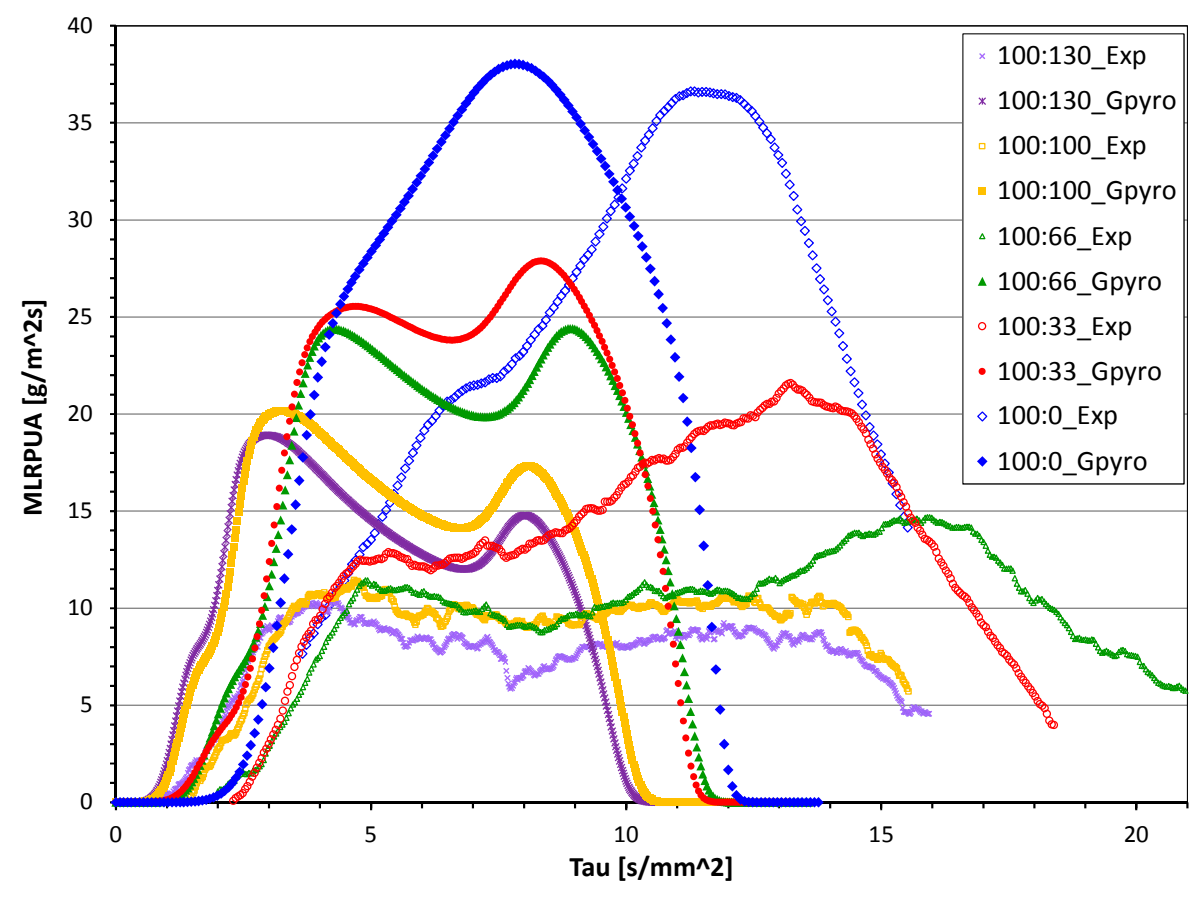

Figure 7. Experimental mass loss rate per unit area (MLRPUA) measured in the Cone Calorimeter and for the Gpyro for each resin and alumina trihydrate (ATH) mixture (Tau is the time divided by sample thickness squared).

Figures 8 and 9 show the experimental and simulated temperatures on the exposed and unexposed faces respectively, and clarify the limits of the current fire testing simulations.

The Cone experiments show that both the exposed and unexposed face temperature histories for all resin and ATH mixtures are similar (within $100{ }^{\circ} \mathrm{C}$ ). The Gpyro simulated histories for the exposed and unexposed face for all resin and ATH mixtures are also similar. For the exposed face, the simulated temperatures are significantly lower (approximately $150{ }^{\circ} \mathrm{C}$ ) than the measured histories. For the unexposed face, the simulated temperatures are similar to the measured histories. A likely reason for the lower exposed face simulated temperatures is due to the lack of a simulated flame heat flux after ignition. Sample ignition occurs around Tau equal to $2 \mathrm{~s} / \mathrm{mm}^{2}$. The flame heat flux is in the range up to $20 \mathrm{~kW} / \mathrm{m}^{2}$ [30]. If the IHF in the simulations was increased from $50 \mathrm{~kW} / \mathrm{m}^{2}$ up to $70 \mathrm{~kW} / \mathrm{m}^{2}$ the simulated exposed face temperature would then be similar to that measured in the 
Cone. However, the simulated MLRPUA would increase as compared to the above values and show a greater difference between measurements and simulations.

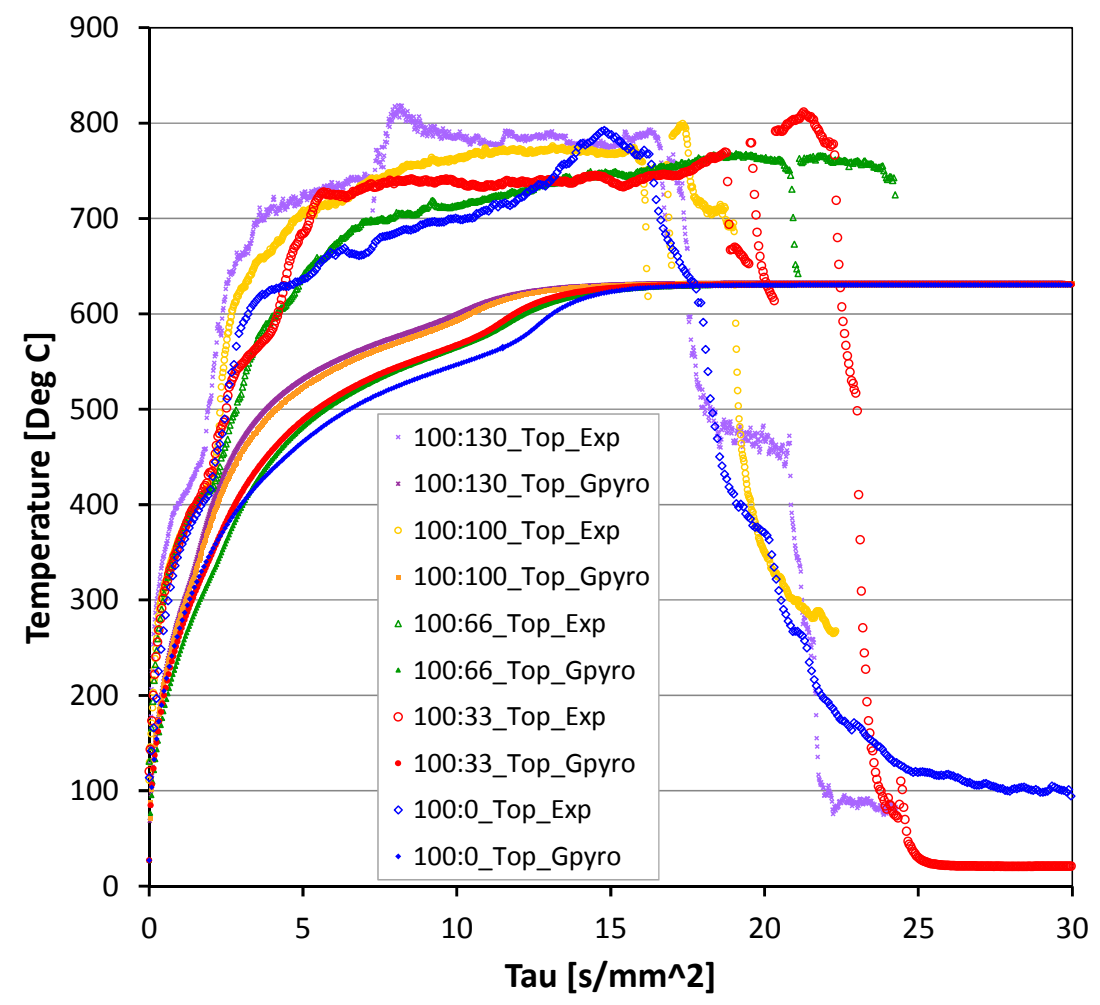

Figure 8. Experimental and simulated exposed face temperatures (Tau is the time divided by sample thickness squared).

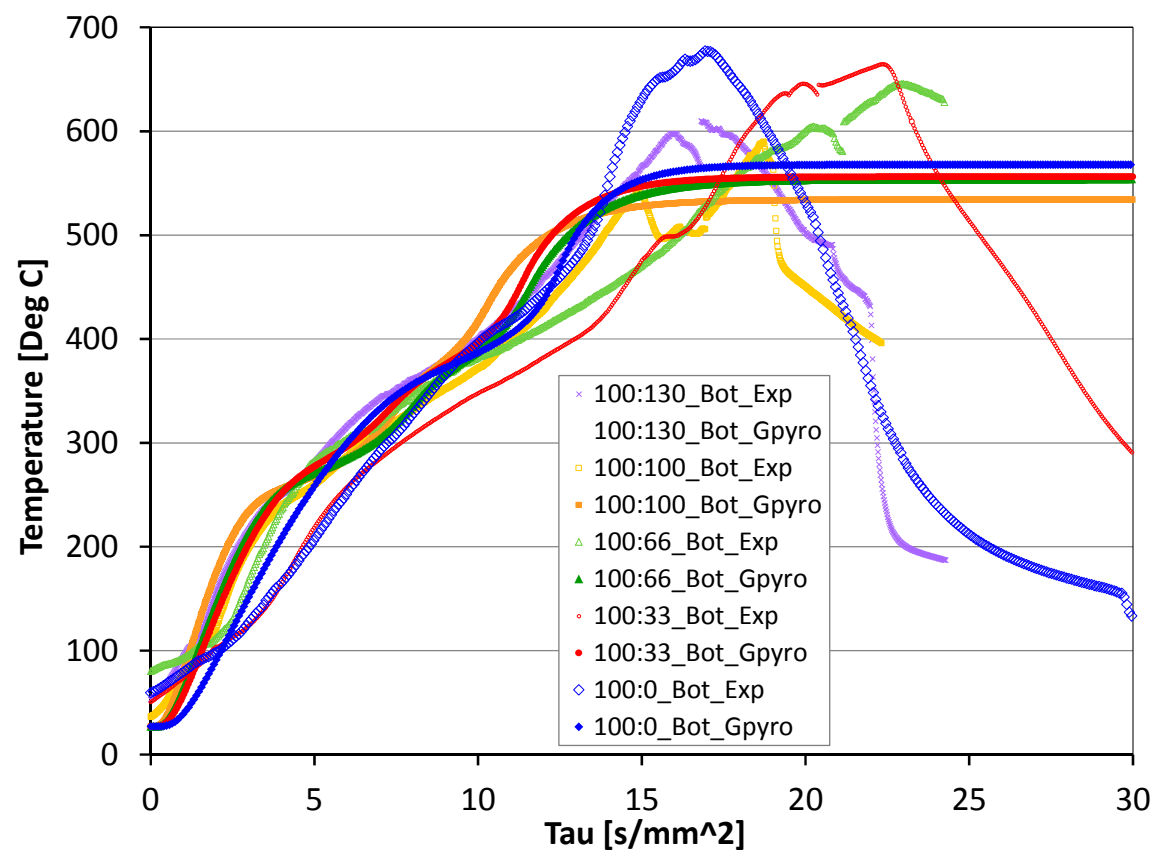

Figure 9. Experimental and simulated unexposed face temperatures (Tau is the time divided by sample thickness squared). 


\section{Conclusions}

Given architects interest in FRPs as a modern building material, understanding non-structural behavior of FRPs is important. Two non-structural aspects of FRPs have been discussed: the low thermal transmissibility and the simulated fire pyrolysis behavior.

Simulation of FRP fire behavior using simple correlations and bench scale tests such as the Cone Calorimeter were discussed as practical screening tools. More fundamental simulation of FRP pyrolysis was discussed based on simulations using the Gpyro model. The ability to simulate a class of FRP systems was evaluated. This evaluation focused on the decomposing parts of the FRP: resin and ATH.

Based on previously estimated pyrolysis parameters, the mass loss rate (MLRPUA) and sample surface temperatures were simulated in Gpyro. In comparison to measurements, Gpyro significantly over estimates MLRPUA and produces similar temperatures. These results show that Gpyro is able to qualitatively account for the changing resin to ATH ratios indicating that as a design tool Gpyro can be used for screening purposes but not yet for simulation of specific fire tests.

Future work is needed to develop porous media input parameters to evaluate Gpyro model ability to simulate the effects of the blockage layer (resin and ATH residue) formation as a function of ATH loading. Simulation of flame heat flux should also be included. Including these missing physical aspects of pyrolysis would allow for a better understanding of the general applicability of the various species parameters of FRPs.

Acknowledgments: The authors would like to acknowledge Caitlin Walde, Brianna Gillespie, and Randall Harris for their excellent work conducting the Cone Calorimeter experiments. The authors would like to acknowledge Tanner Buxton for his help with the Gpyro simulations. The authors would also like to thank Dan Green from Enclos and Kreysler and Associates for allowing publishing the details in Figure 4.

Author Contributions: Umberto Berardi and Nicholas Dembsey declare that they have contributed equally to this work.

Conflicts of Interest: The authors declare no conflict of interest.

\section{References and Notes}

1. Hollaway, L.C. A review of the present and future utilisation of FRP composites in the civil infrastructure with reference to their important in-service properties. Constr. Build. Mater. 2010, 24, 2419-2445. [CrossRef]

2. Kendall, D. Building the future with FRP composites. Reinf. Plast. 2007, 51, 31-33. [CrossRef]

3. Kreysler \& Associates. Architectural Composites, 2013. Available online: http://www.kreysler.com/ category/project/architecture/ (accessed on 5 November 2015).

4. Berardi, U.; Dembsey, N.; Meacham, B.; You, Y. Fire performance of a fiber reinforced polymer wall panel in a single family dwelling. Fire Technol. 2014, 50, 1607-1617. [CrossRef]

5. Berardi, U. Sustainability assessment in the construction sector: Rating systems and rated buildings. Sustain. Dev. 2012, 20, 411-424. [CrossRef]

6. Bakis, C.E.; Bank, L.C.; Brown, V.L.; Cosenza, E.; Davalos, J.F.; Lesko, J.J.; Machida, A.; Rizkalla, S.H.; Triantafillou, T.C. Fiber-reinforced polymer composites for construction-State-of-the-Art Review. J. Compos. Constr. 2002, 5, 73-87. [CrossRef]

7. Osugi, R.; Takagi, H.; Liu, K.; Gennai, Y. Thermal conductivity behavior of natural fiber-reinforced composites. In Proceedings of the Asian Pacific Conference for Materials and Mechanics, Yokohama, Japan, 13-16 November 2009.

8. NFPA 285. Standard Fire Test Method for Evaluation of Fire Propagation Characteristics of Exterior Non-load-bearing Wall Assemblies Containing Combustible Components. National Fire Protection Association: Quincy, MA, USA, 2012.

9. Devendra, K.; Rangaswamy, T. Thermal conductivity and thermal expansion coefficient of gFRP composite laminates with fillers. Mech. Confab. 2013, 2, 39-44.

10. Wang, S.; Qiu, J. Enhancing thermal conductivity of glass fiber/polymer composites through carbon nanotubes incorporation. Compos. Eng. 2010, 41, 533-536. [CrossRef] 
11. Bai, Y.; Vallee, T.; Keller, T. Modeling of thermal responses for FRP composites under elevated and high temperatures. Compos. Sci. Technol. 2008, 68, 47-56. [CrossRef]

12. Bellakehal, H.; Zaidi, A.; Masmoudi, R.; Bouhicha, M. Behavior of FRP bars-reinforced concrete slabs under temperature and sustained load effects. Polymers 2014, 6, 873-889. [CrossRef]

13. Berardi, U.; Wang, T. Daylight in an atrium type high performance house. Build. Environ. 2014, 76, 92-104. [CrossRef]

14. 2015 International Building Code. International Code Council: Birmingham, AL, USA, 2015.

15. ASTM Standard E84. Standard Test Method for Surface Burning Characteristics of Building Materials. ASTM International: West Conshohocken, PA, USA, 2015.

16. ASTM Standard E1354. Standard Test Method for Heat and Visible Smoke Release Rates for Materials and Products Using an Oxygen Consumption Calorimeter. ASTM International: West Conshohocken, PA, USA, 2015.

17. Dembsey, N.A.; Kreysler, W.; Anaya, J.; Herrera, R.C.; Morgan, D. FRP resin and additive effects on fire performance for quality control planning. In Proceedings of CAMX-The Composites and Advanced Materials Expo, Orlando, FL, USA, 13-16 October 2014.

18. Dembsey, N.A.; Stevens, M.; Kreysler, W.; You, Y.G. Exterior Wall Assembly Material Screening Process for NFPA 285. In Proceedings of the Composites 2013, Orlando, FL, USA, 29-31 January 2013.

19. Nguyen, Q.T.; Tran, P.; Ngo, T.D.; Tran, P.A.; Mendis, P. Experimental and computational investigations on fire resistance of GFRP composite for building façade. Compos. Eng. 2014, 62, 218-229. [CrossRef]

20. NIST Special Publication 1019-5. Fire Dynamics Simulator Version 6 User's Guide; National Institute of Standards and Technology: Gaithersburg, MD, USA, 2007.

21. Lautenberger, C.; Fernandez-Pello, C. Generalized Pyrolysis Model for Combustible Solids. Fire Saf. J. 2009, 44, 819-830. [CrossRef]

22. Stoliarov, S.; Li, J. Measurement of kinetics and thermodynamics of the thermal degradation for non-charring polymers. Combust. Flame 2013, 160, 1287-1290.

23. Kim, E.; Dembsey, N.A. Parameter estimation for comprehensive pyrolysis modeling: Guidance and critical observations. Fire Technol. 2015, 51, 443-477. [CrossRef]

24. Stoliarov, S.I.; Li, J. Parameterization and validation of pyrolysis models for polymeric materials. Fire Technol. 2015. [CrossRef]

25. Kim, E.; Dembsey, N.A.; Shivkumar, S. Evaluating effects of applying different kinetic models to pyrolysis modeling of fiberglass reinforced polymer composites. Fire Mater. 2015, 39, 153-173. [CrossRef]

26. Kim, E.; Dembsey, N.A. Evaluation of pyrolysis parameters for fiberglass reinforced polymer composites based on multi-objective optimization. Fire Mater. 2014. [CrossRef]

27. ASTM D3850. Standard Test Method for Rapid Thermal Degradation of Solid Electrical Insulating Materials by Thermogravimetric Method TGA. ASTM International: West Conshohocken, PA, USA, 2015.

28. ASTM D3418. Standard Test Method for Transition Temperatures and Enthalpies of Fusion and Crystallization of Polymers by Differential Scanning Calorimetry. ASTM International: West Conshohocken, PA, USA, 2015.

29. Dembsey, N.A.; Gillespie, B.; Long, M.; McMillan, N.; Walde, C.; Kreysler, W. Pyrolysis simulation of fiber reinforced polymer FRP composites: Challenges of zero-dimensional testing of resin and additive mixtures to measure kinetic parameters. In Proceedings of the 14th International Conference on Fire and Materials, San Francisco, CA, USA, 2-4 February 2015.

30. Beaulieu, P.A.; Dembsey, N.A. Effect of oxygen on flame heat flux in horizontal and vertical orientations. Fire Saf. J. 2008, 43, 410-428. [CrossRef]

(C) 2015 by the authors; licensee MDPI, Basel, Switzerland. This article is an open access article distributed under the terms and conditions of the Creative Commons by Attribution (CC-BY) license (http://creativecommons.org/licenses/by/4.0/). 